during the past 13 years in Canada where, have great difficulty in affording to smoke? possibly because an actual fee for the surgery -I am, etc., is involved, the situation is more individualized and contractual, with the consequent possibility of litigation in the event of failure. Therefore for personal and legal reasons I could not guarantee sterility if any spermatozoa-motile or non-motile-were present in the semen. In the early years I required only one negative specimen but later increased this to two. Because of two pregnancies, with motile spermatozoa, I have for the past five years followed a routine of two negative specimens, two weeks apart, two months after the operation followed by a third negative specimen one month later. Thus the patient and $I$ are satisfied that every reasonable precaution has been taken. If a specimen shows any sperm, then specimens are repeated monthly for 8-12 months. At the end of this variable period a second operation is performed as before under local anaesthetic with no difficulty, using a fresh site on the vas if there is any granulomatous tissue formation from the previous surgery. A total of 14 patients, 12 with non-motile sperm and two with large motile sperm counts, had repeat vasectomies performed and in every case was aspermic one month after operation.

It was noted that, generally speaking, the older the patient, the longer the period required to attain azoospermia, the oldest (75 years) taking 18 months. While I have a routine based on a period of time, the vital factor is the frequency of coitus, which in the older patient with failing sexual function requires more time and more ejaculations to complete evacuation of the spermatozoa. The time schedule was strictly adhered to in order that if recanalization takes place, which is more probable in the first two months, it will show up in the routine tests. It would appear that sperm present in the semen after 50 intercourses indicates recanalization, and reoperation should be considered. Intermittant aspermia may be due to a temporary blockage of a recanalizing vas. No third vas was encountered and it is probable that its functional existence is to provide the surgeon with a reason to give the patient for failure to attain sterility.

It is unlikely and unethical that the question whether a patient with non-motile sperms in his specimen is capable of impregnationother specimens may contain motile spermatozoa-will be resolved as it is not in the interest of the patient, his wife, or the child to prove that the husband is not the father. If the doctor is not aware of this the patient and his wife are, and will refuse the confrontation and consequences.-I am, etc.,

Ardfern by Lochgilphead,

E. S. LIVINGSTONE Argyll

\section{Lung Cancer and Smoking}

SIR,-After the latest depressing news about the increase in cigarette smoking I consider it inevitable that eventually legislation will have to be introduced prohibiting the use of tobacco or limiting its use to registered addicts only.

Should not the B.M.A. start now and lobby the Government seriously to consider legislation, or at least increase the prices so much that children under 14 years would
Hemel Hempstead.

R. C. HOBBS lipids. ${ }^{6}$

The phenomenon to which Dr. F. M. Martins and his colleagues draw attention (8 September, p. 544) is interesting and deserves further study, but we cannot yet assume that those newborn babies with relatively high triglyceride levels in cord blood will be the individuals who show the better known primary type IV hyperlipoproteinaemia in middle age. Careful and prolonged follow-up is needed and it could yet turn out that the cause of "newborn type IV hyperlipoproteinaemia" is obstetrical (in the broadest sense of the word) rather than genetic. monstrate tubal patency during diagnostic laparascopy. The usual preparation is methylene blue injection, U.S.P., $1 \%$ in water in 10-ml ampoules (Harvey Laboratories, Inc., Philadelphia). The $\mathrm{pH}$ is 6.07. I wish to emphasize that this should be diluted liberally. Because the colour is very strong 1 $\mathrm{ml}$ diluted in $1000 \mathrm{ml}$ of sterile normal saline is sufficient to show clearly after spill into the peritoneal cavity.

An average injection would be $10 \mathrm{ml}$ and if given undiluted, straight from the ampoule, can provoke an acute reaction with signs of pelvic peritonitis lasting for some weeks, presumably following a "chemical salpingitis." There is also the problem of leakage into uterine blood vessels. The manufacturer's leaflet relating to intravenous administration of undiluted dye specifies the precaution of slow injection over minutes of a dose calculated on a body weight basis and mentions adverse reactions of nausea, abdominal and precordial pain, dizziness, headache, profuse sweating, mental confusion, and the formation of methaemoglobin.-I am etc.,

Department of Obstetrics and Gynaecology,

J. C. O’Sullivan Hammersmith Hospital,
London $W .12$

\section{Type IV Hyperlipidaemia in Cord Blood}

SIR,-Though Kwiterovitch et al., ${ }^{1}$ have recently reported triglyceride concentrations in cord blood averaging $37 \mathrm{mg} / 100 \mathrm{ml}$, with a standard deviation of only $15 \mathrm{mg}$, in 36 normal infants, evidence was published 11 years ago that a proportion of newborn babies have relative hypertriglyceridaemia. Brody and Carlson $^{2}$ measured triglycerides and other lipids in cord blood from 52 unselected newborn infants. The mean concentration of their plasma triglycerides was $0.38 \mathrm{mmol} / 1$. (approximately $33 \mathrm{mg} / 100 \mathrm{ml}$ ) but the frequency distribution was significantly skewed to the right-so that a standard deviation could not be calculated-and values ranged up to $0.85 \mathrm{mmol} / 1$. or $74 \mathrm{mg} / 100 \mathrm{ml}$. The upper tail of the distribution might, if one wished, be called relative type IV hyperlipidaemia in the newborn.

Brody and Carlson suggested that genetic factors could be responsible for this phenomenon. However, the last weeks of pregnancy and birth itself are a time of stress and metabolic changes whose intensity varies between individuals. Some degree of fatty liver appears to be quite common in the newborn. ${ }^{4}$ Pre- $\beta$-lipoprotein, which carries endogenous triglycerides in plasma, is the predominant lipoprotein in cord blood but its concentration falls off during the first few days of life, while that of $\beta$-lipoprotein increases. ${ }^{5}$ There are accompanying major
A. S. TRUSWELI

Queen E

London $\mathbb{W} .8$

1 Kwiterovitch, P. O., jun., Levey, R. I., and Fredrickson, D. S., Lancet, 1973, 1, 118 . Chimica Acta, 1962, 7, 694 .

Dorkin, J. R., and Weinberg, T., Archives of Pathology, 1949, 48, 578 54, 378.

Friis-Hansen, B. and Clausen, J., Zeitschrift fur Ernährungswissen-schaft, 1971, 10, 253.

6 Clausen, J., and Friis-Hansen, B., Zeitschrift fur Ernährungswissen-schaft, 1971, 10, 264.

\section{Drug-induced Platelet Antibodies}

SIR,-We read with interest the letter of Drs. C. Davidson and S. M. Manohitharajah (8 September, p. 545), who reported the presence of specific platelet antibodies in a patient who developed thrombocytopenia while receiving phenylbutazone therapy. With the increasing incidence of druginduced blood dyscrasias it would appear to be more and more relevant to search for mediating antibodies and we would like to report another illustrative case.

A 77-year-old woman presented with a 24-hour history of epistaxis and rectal bleeding, with spontaneous bruising for two weeks. She had been taking phenylbutazone regularly for 12 years to alleviate arthritic pain and for three years she had been taking quinine sulphate as treatment for nocturnal cramps. We were unable to ascertain any recent alteration in dosage or proprietary brand. ized bruising and purpura over the limbs and trunk. Petechial haemorrhages in the mouth and a flame haemorrhage in the left fundus were noted, together with evidence of recent epistaxis and rectal bleeding. There were no other abnormal clinical findings. leucocyte count $1,200 / \mathrm{mm}^{3}$, and platelet count $10,000 / \mathrm{mm}^{3}$. Bone marrow aspiration revealed a mildly hypocellular marrow with macronormoblastic erythropoiesis and delayed maturation of granulopoiesis. Megakaryocytes showed reduced platelet budding. There was no evidence of bone marrow infiltration. Tests for antinuclear factor and L.E. cells were negative, as were Ham's test and screening for urinary haemosiderin. Serum vitamin $B_{12}$ and folate levels were normal. The Direct Coombs test was negative. Tests for leucocyte and platelet agglutinins were also negative, but complement fixation test was strongly positive for incomplete platelet antibodies in the presence of quinine sulphate. This was negative in the presence of phenylbutazone.

All drugs were withheld and, apart from reverse barrier nursing, no active therapy was given. After eight days her haemoglobin level had risen to $10.3 \mathrm{~g} / 100 \mathrm{ml}$, total leucocyte count to $4,600 / \mathrm{mm}^{3}$, $10.3 \mathrm{~g} / 100 \mathrm{ml}$, total leucocyte count

It would appear that the pancytopenia resulted from the combined effects of phenyl-
Department of Nutrition,

Benitez, M. R. E., Archives of Pathology, 1952, Examination revealed a pale woman with general-

Her haemoglobin level was $9.7 \mathrm{~g} / 100 \mathrm{ml}$, total 